\title{
SELF ASSESSMENT EXERCISES
}

Series Editor Surgeon Lieutenant Commander J E Smith

\section{Self Assessment Exercises in General Practice}

\author{
JE Smith, AM McCaldin
}

\section{Introduction}

You are a Medical Officer working in a triservice primary care establishment. The following patients present to your surgery.

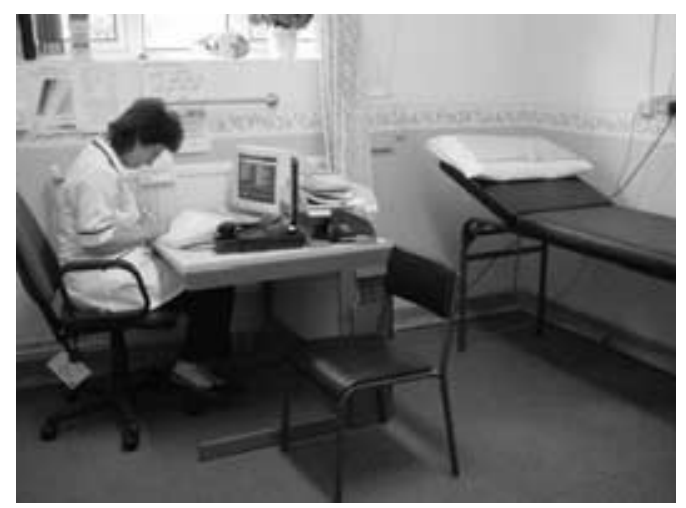

\section{Questions}

1. A 25 year old soldier comes into your surgery complaining that he has been feeling very depressed lately, and confesses that he has been thinking of trying to commit suicide. He admits to writing a suicide note, and buying a supply of painkillers with which he plans to attempt an overdose. He refuses admission to hospital for assessment.

\section{Question a.}

What can you do to enforce treatment? Question b.

What assistance will you require?

Surgeon Lieutenant Commander J E Smith MBBS, MRCP, Royal Navy

Specialist Registrar in Accident and

Emergency Medicine

Royal London Hospital, Whitechapel, London

\section{E1 1BB.}

Major A M McCaldin MBBS, DCH, DRCOG, RAMC. Regimental Medical Officer

1st Battalion Royal Anglian Regiment
2. In your morning surgery you review a 45 year old Scots Guard whom you first saw the previous week. He had originally come to see you because his father had died from a myocardial infarction at the age of 53, and he was concerned that he might be at risk of a similar fate himself. He had no symptoms of ischaemic heart disease, although he did admit to smoking 20 cigarettes a day, and taking a poor diet. He said he drank alcohol "socially". His maternal grandfather also died in his 50's from ischaemic heart disease.

You had initiated a series of investigations at his last visit. Physical examination was unremarkable. Blood pressure 120/80. Resting 12 lead ECG was normal. You sent some blood to the laboratory for investigation, the results of which you now

\begin{tabular}{|c|c|}
\hline Full Blood Count & $\begin{array}{l}\text { MCV 98, otherwise } \\
\text { normal }\end{array}$ \\
\hline Urea and electrolytes & normal \\
\hline Cholesterol & $7.2 \mathrm{mmol} / \mathrm{l}$ \\
\hline
\end{tabular}

\section{Question a.}

List three possible causes for his macrocytosis, and further investigations you may perform to establish the cause.

Question b.

What lifestyle advice would you give him? Question c.

Would drug treatment of his hypercholesterolaemia be appropriate? Give reasons.

3. A 23 year old soldier attends your surgery with a colleague. That morning he had been watching television when he had suffered an episode of collapse with loss of consciousness and he is unable to recall anything else until he remembers coming around lying on the floor. His colleague, who witnessed the episode, describes what sounds like a generalised tonic-clonic convulsion. There was no preceding aura, and no associated injuries, although he had been incontinent of urine. Afterwards, he was confused and dazed for about an hour, but by the time you see him he says he feels back to normal.

\section{Question a.}

What initial investigations are indicated? Question b.

What should you advise the patient with regard to driving?

\section{Question c.}

Does the patient need acute admission to hospital for further investigation?

4. You receive a telephone call from the accommodation block where most of the new intake of recruits are living. The caller requests that you visit an 18 year old recruit who is too ill to get to the medical centre.

On your arrival, you see that the recruit in question is in bed, appears drowsy and confused, and is soaked in sweat. You are unable to get a coherent history from him, but one of his colleagues says he woke earlier complaining of a headache.

Examination reveals a temperature of 38 degrees Celsius, pulse of 100 and BP of $100 / 60$. The recruit is confused and 
disorientated, but there is no evidence of focal neurological deficit. You notice a haemorrhagic rash on his lower limbs.

\section{Question a.}

What is your provisional diagnosis?

Question b.

What would you do?

Question c.

What other measures, with regard to possible contacts, should be taken?

5. A 45 year old sergeant presents to your surgery with a worsening history of dyspepsia. A recent endoscopy showed a small gastric ulcer, biopsies of which showed no evidence of malignancy. He was treated initially with omeprazole $20 \mathrm{mg}$ once daily with some improvement, but now his symptoms have worsened again. You have received a report from the local microbiology laboratory saying that serology for Helicobacter pylori is positive.

\section{Question a.}

Is serology a reliable test for the presence of $\mathrm{H}$ pylori?

Question b.

What treatment is appropriate, and in what form would you initiate this treatment?

Question c.

Is the same treatment indicated for nonulcer dyspepsia associated with $\mathrm{H}$ pylori infection?

6. A 35 year old soldier's wife attends the families' clinic complaining of menorrhagia. She describes heavy menstrual blood loss lasting 10 days of each cycle, which considerably restricts her social life. She has had two normal deliveries and is currently using a Copper T intrauterine device for contraception. She has heard from her friends that going back on the pill may help her bleeding, but she is a smoker and admits there is no way she can give up.

\section{Question a.}

Name two non-hormonal drugs of proven benefit in the management of menorrhagia. Question b.

What form of contraception other than the pill may be of benefit for her?

\section{Question c.}

What would be her risk of pill-related death at this age?

7. A 22 year old female soldier requests a repeat prescription of her oral contraceptive pill. She has taken Femodene (a third generation oral contraceptive pill) without any problems for 5 years, and her blood pressure is $125 / 70$. She has never had a smear, and does not have a regular partner at present, but is sexually active.
Question a.

By what age should a sexually active woman have had her first smear, and what other test might you suggest at the same time for this patient?

Question b.

What is her current risk of thromboembolism? How does this compare to the risk associated with second generation oral contraceptive pills and pregnancy?

Question c.

Which drugs commonly reduce the effectiveness of an oral contraceptive pill?

\section{Answers to self assessment questions}

\section{Question 1.}

a. Invoke section 2 or section 4 of the Mental Health Act (1983 England and Wales)

b. For Section 4 no assistance is required but Section 2 requires two doctors, one of whom should preferably be a psychiatrist.

\section{Discussion}

In part II of the Mental Health Act (1983 England and Wales) civil detention orders are specified. The patient must be suffering from a mental disorder that warrants detention in hospital in the interests of their own safety or the safety of others. Section 4 deals with the emergency admission of a patient for assessment, and requires the recommendation of one doctor, who should preferably be acquainted with the patient. This order lasts for up to 72 hours, but is not renewable. Section 2 deals with detention of a patient for up to 28 days, which is obviously preferable, but requires the signature of two doctors, one of whom should preferably be a psychiatrist. In the military, there is the added facility to detain a serviceman without charge in the guardroom (or equivalent) for his own safety, an option that may facilitate the arrangement of a second medical opinion. The Army Act (1981), in section 13, outlines procedures very similar to the Mental Health Act. It allows admission and treatment against the patient's will to a military secondary care facility, and outlines two types of detention, the first lasting 5 days requiring one Medical Officer, the second lasting 28 days requiring two Medical Officers, of whom one should be a psychiatrist. The application for the section should be made by the Commanding Officer.

\section{Question 2.}

a. Any of the following may cause a macrocytosis, but in this case the first is most likely:

- alcohol 
- vitamin B12 or folate deficiency

- hypothyroidism

- terminal ileal disease e.g. Crohn's disease

- drugs e.g. anticonvulsants

- haemolytic / aplastic anaemias

Liver function tests, in particular gamma glutaryl transferase (yGT), should be performed, along with a haematinic screen and thyroid function tests.

b. He should give up smoking. The most likely reason for his macrocytosis is alcohol - identification of an alcohol problem can be facilitated by using either the CAGE or MAST questionnaires (Mayfield et al 1974, Pokorny et al 1972), and he should be offered counselling with regard to reducing his alcohol intake. His diet should be modified as far as possible, and his blood pressure monitored on a regular basis.

c. Yes, treatment with a statin - see discussion.

\section{Discussion}

This question is in two parts. The first is a relatively simple spot diagnosis from a set of haematological results, with alcohol being by far the most likely cause of an isolated macrocytosis in an otherwise healthy patient with an otherwise normal full blood count.

The second part of the question is much more complex, and illustrates the problem of treatment of asymptomatic hypercholesterolaemia in a high risk patient. If the Sheffield tables (Ramsay et al 1996) are used, a smoking male does not warrant treatment until his mid 50's. However, this patient is at high risk of coronary heart disease due to his strongly positive family history, and presumed familial hyperlipidaemia. The patient's background puts him in the population group studied by Shepherd et al in the West of Scotland Coronary Prevention Study (1995). This showed a $30 \%$ reduction in coronary events after treatment of raised cholesterol in otherwise asymptomatic patients. $\mathrm{He}$ would also fall in the third priority group described by the Standing Medical Advisory Committee in their guidelines published in 1997, of people without clinically apparent vascular disease but who, nevertheless, have a high risk of developing coronary heart disease. Most cardiologists would agree that this patient falls into a category that should be treated with a statin. It would be reasonable to give lifestyle and dietary advice to this patient, and repeat the lipid screen on a fasting sample after a few weeks. If still raised treatment with a statin should be commenced. If there is doubt as to whether or not the initiation of statin treatment is appropriate in other patients a specialist opinion should be sought.

\section{Question 3.}

a. a full neurological examination and blood glucose (BM stix) measurement.

b. he should not drive for one year, and it is his duty to inform the DVLA.

c. no - urgent outpatient referral is appropriate (see discussion)

\section{Discussion}

This patient has presented following a witnessed first fit. The patient is otherwise well, has no history of similar episodes, and has returned to his pre-morbid state, with no neurological deficit. The question addresses the issue of how much, and when, to investigate. The literature surrounding the subject differs in opinion, and there is no clear guidance. Turnbull et al (1990) recommended that the only investigation necessary in this group of patients is a blood glucose measurement, taking into account the normal medical history and examination. This would seem a sensible approach to take as the limit of initial investigation. The patient should then be referred as an out-patient for further assessment by a neurologist or physician. Most patients receive a CT scan, EEG, and screening blood tests at this stage.

With regard to driving, his driving licence will be revoked for a period of 12 months initially, and it is his duty to inform the DVLA of what has happened.

The DVLA guidelines are found in "Medical Aspects of Fitness to Drive", Chapter 6.

\section{Question 4.}

a. acute bacterial meningitis (meningococcal meningitis)

b. resuscitate as necessary, give $1.2 \mathrm{~g}$ benzylpenicillin IV then arrange an emergency ambulance to transport to the nearest emergency department.

c. prophylaxis with rifampicin or ciprofloxacin.

\section{Discussion}

The treatment of a patient with suspected acute bacterial meningitis is now described by international guidelines and should be standard. Treatment with a stat dose of benzylpenicillin 1.2g IV (cefotaxime is an alternative if penicillin allergic) and urgent transfer to the nearest $\mathrm{A} \& \mathrm{E}$ department is the treatment of choice (Begg et al 1999, Moller and Skinhoj 2000). The problem of giving prophylaxis to contacts is slightly more contentious. The recommendation is that contacts should receive prophylaxis in the form of either rifampicin $600 \mathrm{mg}$ bd for 48 hours or ciprofloxacin $500 \mathrm{mg}$ as a oneoff dose. In situations where compliance is deemed to be a problem, such as in a college campus environment, it is often easier to give ciprofloxacin to ensure 
adequate cover. This would also be an option in a military mess environment, especially if young recruits are about to disappear on weekend leave. If in doubt, advice should be sought from the local centre for infectious diseases.

\section{Question 5.}

a. It is a reliable test for the presence of antibodies to $\mathrm{H}$ pylori, but this does not necessarily mean that there is current infection as antibodies may persist for several years following eradication therapy. However, given this history, it is likely to represent current infection.

b. Triple therapy for $\mathrm{H}$ pylori eradication: amoxycillin $1 \mathrm{~g}$ bd + clarithromycin $500 \mathrm{mg}$ bd + omeprazole $20 \mathrm{mg}$ bd (or similar regimen, see discussion).

c. Possibly - see discussion.

\section{Discussion}

Helicobacter pylori was discovered by Warren and Marshall in 1984, and there is now strong evidence pointing to a causative relationship between this organism and peptic ulcer disease. Prior to this discovery peptic ulcer disease could be treated with some success with $\mathrm{H} 2$ antagonists or proton pump inhibitors, but the relapse rate often exceeded $50 \%$. With eradication therapy this relapse rate is less than $5 \%$ per year.

There are now reliable tests, both invasive and non-invasive, to establish the presence of infection. The radio-labelled carbon-urea breath test is positive in ongoing infection in more than $85 \%$ of cases, and the diagnosis of infection is often made at endoscopy by performing a urease based assay on a sample of gastric mucosa taken at biopsy.

A variety of $\mathrm{H}$ pylori eradication regimens have been investigated, and to some extent the choice of regimen will depend on local factors such as availability, cost and compliance. A one week regimen including a proton pump inhibitor, clarithromycin, and either metronidazole or amoxycillin is recommended in the current British National Formulary (March 2000, pp3637 ), achieving eradication rates of over $90 \%$, at a cost of about $£ 40$.

A recent meta-analysis (Jaakkimainen et al 1999) discusses the association between $\mathrm{H}$ pylori and non-ulcer dyspepsia and asks whether eradication will improve symptoms. The paper suggests that there is a strong association, and that eradication improves symptoms, but the paper caused some controversy, with a number of letters questioning the validity of the meta-analysis arising in subsequent issues of the BMJ. The jury still appears to be out.

\section{Question 6.}

a. Mefanamic acid and tranexamic acid.

b. A progestogen releasing intrauterine device. c. Smokers over 35 have an incidence of pill-related death of 3 in 500 .

\section{Discussion}

This question deals with two separate issues. The first is the treatment of menorrhagia, which is often dealt with by using the combined pill. However, in this case, the risks of pill-related complication is high, so other treatments should be considered. Non-hormonal management of menorrhagia is possible using the two agents in (a). The mechanism of action is different in each case. Mefanamic acid and some other NSAIDs inhibit prostaglandin synthesis and have been shown to reduce blood flow by $20-30 \%$, as well as having beneficial effects by reducing dysmenorrhoea. Tranexamic acid is an antiplatelet agent that has been shown to significantly reduce blood loss by as much as $50 \%$ in some cases (Bonner, Sheppard, 1996).

Devices such as the Levonorgestrel Intrauterine System, which is an IUD containing levonorgestrel in a slow release polymer, deliver small amounts of progestogen to the endometrium (20 micrograms of levonorgestrel into the uterine cavity over 24 hours). This has been shown to cause a dramatic reduction in blood loss due to a local effect on the endometrium, but may take some time to have its effect (Guillbaud 1999).

The second part of the question deals with pill-related death in smokers. Between the ages of $15-34$, the risk of pill-related death is 5 in 10,000, (as opposed to 1 in 10,000 for non-smokers). After the age of 35, the risk increases to 3 in 500 (as opposed to 1 in 500 for non-smokers).

\section{Question 7.}

a. By the age of 20. Chlamydia trachomatis.

b. 30 in 100,000 (see discussion).

c. any enzyme-inducing drugs or broad spectrum antibiotics, the most commonly used being

- antibiotics especially rifamycins and broad spectrum e.g. ampicillin

- anticonvulsants e.g. phenytoin, carbamazepine

- ulcer-healing drugs eg. lansoprazole

- antifungal agents e.g. griseofulvin

\section{Discussion}

The National Co-ordinating Workshop Guidelines 1992 and the report of the RCOG Intercollegiate Working Party 1987 concerning the frequency of cervical smears advises that all women aged 20 - 64 should have smears repeated at 3 yearly intervals. There is no upper age limit if a patient has never had a smear, and currently there is no recommendation for teenagers to be 
"smeared". A sexually active patient of this age is at risk of infection with Chlamydia trachomatis. This infection is highly significant due to its potential to cause future infertility despite the lack of clinical symptoms. Substantial under-diagnosis and reporting make accurate estimation of risk difficult, but infection rates in the 16-25 yr old age group are thought to be between $10-15 \%$. If the patient is agreeable, testing for this infection and appropriate treatment with antibiotics may be of value and should be considered.

The patient's risk of thromboembolism of 30 in 100,000 compares with the risk of a thromboembolic episode with a second generation contraceptive pill of 15 in 100,000. The risk of a thromboembolic episode in pregnancy is 60 in 100,000, suggesting that despite the increased risk with the third generation oral contraceptive pills, the risk is still lower than that of a pregnancy.

The list of drugs affecting the efficacy of the combined pill is by no means exhaustive, but includes some of the more common agents used in practice.

\section{References}

1. Army Act 1981 Vol II Ch 66 pp. 411-435 AGAIs.

2. Begg $\mathrm{N}$ et al. Consensus statement on diagnosis, investigation, treatment and prevention of acute bacterial meningitis in immunocompetent adults. f Infect 1999; 39: 1-15.
3. Bonnar J, Sheppard BL. Treatment of menorrhagia during menstruation: randomised controlled trial of ethamsylate, mefanamic acid and tranexamic acid. BMF 1996; 313: 579-582.

4. British National Formulary. March 2000.

5. Guillebaud J. "Contraception, your questions answered" 3rd edition. 1999. Churchill Livingstone Press, ISBN 0-443-06153-X.

6. Jaakkimainen RL, Boyle E, Tudiver F. Is Helicobacter Pylori associated with non-ulcer dyspepsia and will eradication improve symptoms? A meta-analysis. BMF 1999; 319: 1040 - 1044.

7. Marshall BJ, Warren JR. Unidentified curved bacilli in the stomach of patients with gastritis and peptic ulceration. Lancet 1984; i: 1311 1315.

8. Mayfield et al. The CAGE questionnaire: validation of a new alcoholism screening instrument. Am f Psychiatry 1974; 131: 1121-4.

9. Moller K, Skinhoj P. Guidelines for managing acute bacterial meningitis. BMF 2000; 320: 1290.

10. Pokorny et al. The brief MAST: a shortened version of the Michigan Alcoholism Screening Test. Am f Psychiatry 129: 342-5. 1972.

11. Ramsay LE et al. The Sheffield table for primary prevention of -7 . Coronary Heart Disease: corrected. Lancet 1996; 348:1251-2.

12. Shepherd J et al. Prevention of coronary heart disease with pravastatin in men with hypercholesterolaemia. N Engl f Med 1995; 333: 1301

13. Standing Medical Advisory Committee. "The use of statins" 1997.

14. The Medical Commission on Accident Prevention. "Medical Aspects of Fitness to Drive" Chapter 6.

15. Tunkel AR, Scheld WM. Acute bacterial meningitis. Lancet 1995; 346:1675 - 1680

16. Turnbull TL et al. Utility of laboratory studies in the emergency department patients with new onset seizures. Ann Emerg Med 1990; 19: 373-377. 